\title{
Evaluation of ADA activity as a potential marker of disease severity in psoriasis patients
}

This article was published in the following Dove Press journal:

Psoriasis: Targets and Therapy

\author{
Seraj Ahmed Khan' \\ Sudha Agrawal ${ }^{2}$ \\ Nirmal Baral' \\ Madhab Lamsal' \\ 'Department of Biochemistry, B.P. \\ Koirala Institute of Health Sciences, \\ Dharan, Nepal; ${ }^{2}$ Department of \\ Dermatology and Venereology, B.P. \\ Koirala Institute of Health Sciences, \\ Dharan, Nepal
}

Background: Psoriasis is a dermatological disorder with a multifactorial origin and is associated with many biochemical and immunological changes.

Purpose: This study aimed to examine the association of serum ADA activity, uric acid (UA), and high-sensitivity CRP (hs-CRP) with psoriasis and the role of ADA in disease severity.

Materials and methods: In this comparative cross-sectional study, 50 clinically and histopathologically diagnosed psoriasis patients and 50 age- and sex-matched healthy controls were enrolled. Blood samples were taken and analysis of the biochemical parameters was performed according to Giuisti and Galanti method, uricase and ELISA technique for ADA activity, UA, and hs-CRP, respectively. The severity of the disease was scored according to Psoriasis Area and Severity Index (PASI). Statistical analysis of differences within and between the study groups was carried out using the Student's $t$-test, one-way post hoc ANOVA, and Pearson's correlation. Linear regression was used to establish the independent association of ADA with disease severity. Results: The serum ADA activity, UA, and hs-CRP levels of the psoriatic patients were found to be significantly higher $(P<0.001)$. hs-CRP was positively correlated with ADA and UA in patients $(P<0.001)$. There was no significant difference in total cholesterol, low-density lipoprotein, and triacylglycerol in psoriasis patients, whereas we noted a decreased high-density lipoprotein level in psoriasis patients as compared to controls. Linear regression showed that ADA was independently associated with the disease severity and was statistically significant $(P<0.001)$. Conclusion: ADA activity was positively and significantly associated with the severity of psoriasis, therefore, it could be suggested as a marker for disease severity in psoriasis patients. Keywords: adenosine deaminase, C-reactive protein, psoriasis, uric acid

\section{Introduction}

ADA (EC 3.5.4.4) is an enzyme that catabolizes purine nucleotides. It is involved in the hydrolytic deamination of adenosine and 2 -deoxyadenosine to inosine and $2^{\prime}$-deoxyinosine, respectively. The role of ADA in function and maturation of lymphoid cells, especially T-cell lineage, and its altered status in diseases with immunological disturbances have proven to be very crucial and informative. ${ }^{1}$ ADA regulates the plasma adenosine level, which is directly or indirectly involved in inflammatory molecules and cytokine production. The ambiguous nature of ADA gives insight into its involvement in various disorders. ${ }^{2}$

Psoriasis is a chronic skin disorder, with extensive systemic involvement of an unknown etiology. However, the most accepted hypothesis is that it has an immunological involvement due to its association with certain human leukocyte-associated
Correspondence: Seraj Ahmed Khan Department of Biochemistry, B.P. Koirala Institute of Health Sciences, Ghopa Camp, Dharan-18, Distt: Sunsari, Nepal Tel +9779842039061

Email drserajkhan@gmail.com 
antigens, presence of activated $\mathrm{T}$ lymphocytes in lesions, and its response to immunosuppressive therapies. ${ }^{3}$ Various studies have shown elevated ADA activity in epidermis of psoriasis patients. ${ }^{4,5}$ However, this could be due to increased nucleic acid catabolism associated with the hyperproliferative status of epidermis in psoriasis patients. Therefore, the importance of serum ADA may play a significant role in determining the pathogenesis of psoriasis. Similarly, rapid epidermal turnovers may lead to an increased purine breakdown and may influence the serum uric acid level, ${ }^{6}$ and being an inflammatory condition, serum high-sensitivity CRP (hs-CRP) level has also been reported to be elevated in various studies. ${ }^{7}$ However, various conflicting results have been reported from previous studies regarding the role of ADA, uric acid, and hs-CRP. ${ }^{8-10}$ Thus, this study aimed to establish the association of ADA, uric acid, and hs-CRP with psoriasis, and the independent role of ADA in disease severity.

\section{Materials and methods Setting and study design}

This hospital-based, comparative cross-sectional study was conducted over a period of 1 year in the Department of Biochemistry in collaboration with Department of Dermatology and Venereology of B.P. Koirala Institute of Health Sciences, Dharan.

\section{Participants and ethics}

Fifty newly diagnosed cases of psoriasis and 50 age- and sex-matched controls were enrolled in the study. Ethical approval was obtained from the Institutional Ethical Review Board of B.P Koirala Institute of Health Science, Dharan, Nepal. Written informed consent was obtained from the participants before involving them in the study. Patients with psoriatic arthritis, gout, renal disorder, and hypothyroidism were excluded from the study.

\section{Samples}

Blood samples $(5 \mathrm{~mL})$ were collected in plain vials from patients and controls using a standard venipuncture technique. Serum samples were separated immediately after centrifugation at $2,000 \mathrm{~g}$ for 10 minutes and stored at $-20^{\circ} \mathrm{C}$ until the analysis.

\section{Analytical procedures Serum ADA activity}

The ADA activity was measured at $37^{\circ} \mathrm{C}$ according to the method of Giusti and Galanti, ${ }^{11}$ based on the Berthelot reaction, ie, the formation of colored indophenol complexes from ammonia liberated from adenosine, and quantified spectrophotometrically at $625 \mathrm{~nm}$.

\section{Serum uric acid}

Serum uric acid level was estimated by uricase method (Cobas-311 Autoanalyzer, Hoffman-La Roche Ltd., Basel, Switzerland).

\section{Serum hs-CRP}

Serum hs-CRP level was estimated by sandwich ELISA technique (HUMAN, Wiesbaden, Germany).

\section{Statistical analysis}

The values were expressed as mean $\pm \mathrm{SD}$, the median and interquartile range for continuous variables and number and percentage for nominal variables. Normality of the data was tested by Kolmogorov-Smirnov test. Statistical analysis of differences within and between the study groups was carried out using the Student's $t$-test and one-way post hoc ANOVA. Pearson's correlation coefficients were used to determine the relationships between variables. Multiple linear regression models were used for association of independent variables with the disease severity as per Psoriasis Area and Severity Index (PASI) score. The analysis was done by using SPSS version $16.0 . P<0.05$ was considered as statistically significant.

\section{Results}

The psoriasis group $(n=50)$ included 21 females and 29 males with a mean age of $43.26 \pm 10.62$ years (range: $22-66$ years). The control group $(n=50)$ consisted of 25 female and 25 male subjects, with a mean age of $40.62 \pm 9.72$ years (range: $25-65$ years). Differences in age and sex distribution between the two groups were not significant, as in accordance with our selection criteria $(P>0.05)$, as shown in Table 1 . Body mass index (BMI) was similar in both the study groups.

The comparison of the serum ADA activity, hs-CRP uric acid, total cholesterol (TC), triacylglycerol (TAG), low-density lipoprotein (LDL), and high-density lipoprotein (HDL) between patients and controls is depicted in Table 2. ADA activity, hs-CRP, and uric acid level were found to be higher in patients, whereas HDL was lower as compared to control group, and it was statistically significant $(P<0.001)$.

The correlation analysis revealed a significant and positive association between BMI $(P=0.046)$, hs-CRP $(P<0.001)$, uric acid $(P=0.028)$, HDL $(P=0.012)$, and ADA activity in patients (Table 3 ). Multiple linear regression models explained $58 \%$ variance in predicting the severity of the disease by the independent variables and data fit the model 
Table I Basic characteristics of the study participants

\begin{tabular}{llll}
\hline Variables & Psoriasis patients & Controls & P-value \\
\hline Size $(\mathrm{n})$ & 50 & -50 & - \\
Sex & & & - \\
Male, $\mathrm{n}(\%)$ & $29(58)$ & $25(50)$ & \\
Female, $\mathrm{n}(\%)$ & $21(42)$ & $25(50)$ & \\
Age in years & $43.26 \pm 10.62$ & $40.62 \pm 9.72^{\mathrm{a}}$ & $>0.05$ \\
BMI $\left(\mathrm{kg} / \mathrm{m}^{2}\right)$ & $25.63 \pm 3.41$ & $23.38 \pm 2.89^{\mathrm{a}}$ & $>0.05$ \\
Duration (months) & $16.5(12,24)$ & - & NA \\
BSA & $5(2.75,15)$ & - & NA \\
PASI & $6.35(4.1,8.7)$ & - & NA \\
\hline
\end{tabular}

Note: andependent $t$-test, statistically significant at $P<0.05$.

Abbreviations: BMI, body mass index; BSA, body surface area; PASI, Psoriasis Area and Severity Index; NA, not applicable.

Table 2 Comparison of parameters in psoriasis patients and controls

\begin{tabular}{|c|c|c|c|c|c|}
\hline \multirow[t]{2}{*}{ Parameters } & \multicolumn{2}{|c|}{ Psoriasis patients } & \multicolumn{2}{|c|}{ Controls } & \multirow[t]{2}{*}{$P$-value ${ }^{a}$} \\
\hline & Mean & SD & Mean & SD & \\
\hline ADA (U/L) & 31.97 & 13.09 & 17.43 & 8.13 & $<0.001$ \\
\hline hs-CRP (mg/dL) & 3.74 & $\mathrm{I} .4 \mathrm{I}$ & 1.45 & 0.93 & $<0.001$ \\
\hline Uric acid (mg/dL) & 6.71 & 1.34 & 5.22 & 1.6 & $<0.001$ \\
\hline $\mathrm{TC}(\mathrm{mg} / \mathrm{dL})$ & 177.00 & 27.87 & 170.86 & 29.69 & 0.295 \\
\hline TAG (mg/dL) & 160.16 & 47.91 & 155.72 & 31.8 & 0.586 \\
\hline $\mathrm{LDL}(\mathrm{mg} / \mathrm{dL})$ & 123.54 & 21.72 & 120.00 & 19.85 & 0.397 \\
\hline $\mathrm{HDL}(\mathrm{mg} / \mathrm{dL})$ & 40.96 & 8.29 & 47.88 & 9.71 & $<0.001$ \\
\hline
\end{tabular}

Note: aStudent's $t$-test; correlation was significant at the level $P<0.05$.

Abbreviations: hs-CRP, high-sensitivity CRP; TC, total cholesterol; TAG, triacylglycerol; LDL, low-density lipoprotein; HDL, high-density lipoprotein.

Table 3 Correlation of the parameters with ADA in psoriasis patients

\begin{tabular}{lll}
\hline Variables & $\boldsymbol{R}$ value & $\boldsymbol{P}$-value \\
\hline BMI & 0.200 & $0.046^{*}$ \\
hs-CRP & 0.504 & $<0.00 I^{*}$ \\
Uric acid & 0.220 & $0.028^{*}$ \\
TC & 0.013 & 0.895 \\
TAG & -0.02 & 0.813 \\
LDL & 0.059 & 0.561 \\
HDL & 0.250 & $0.012^{*}$ \\
\hline
\end{tabular}

Note: *Correlation is significant at the level $P<0.05 ; r=$ Pearson's coefficient. Abbreviations: BMI, body mass index; hs-CRP, high-sensitivity CRP; TC, total cholesterol; TAG, triacylglycerol; LDL, low-density lipoprotein; HDL, high-density lipoprotein.

significantly. As per the model, ADA and duration were the two independent variables which were significantly associated with the disease severity $(P=0.001$ and $P<0.001)$, as shown in Table 4.

The severity of the disease based on the PASI score was classified as mild (PASI $<10$ ), moderate (PASI $=10-20$ ), and severe (PASI $>20$ ). The ADA, uric acid, hs-CRP, and duration was compared among mild, moderate, and severe groups using one-way post hoc ANOVA and we observed a
Table 4 Multiple linear regression model for PASI score in psoriasis patients

\begin{tabular}{llllll}
\hline Model & Beta & T & P-value & \multicolumn{2}{c}{$\mathbf{9 5 . 0 \% ~ C l ~ f o r ~ B ~}$} \\
\cline { 4 - 6 } & & & & Lower & Upper \\
\hline Constant & & -0.195 & 0.846 & -15.050 & 12.398 \\
Duration & 0.407 & 3.596 & $0.00 I^{\mathrm{a}}$ & 0.128 & 0.454 \\
ADA & 0.482 & 4.348 & $0.000^{\mathrm{a}}$ & 0.142 & 0.388 \\
BMI & -0.144 & -1.392 & $0.17 \mathrm{I}$ & -0.745 & 0.137 \\
hs-CRP & -0.069 & -0.578 & 0.566 & -1.567 & 0.869 \\
Uric acid & 0.028 & 0.274 & 0.785 & -0.971 & 1.277 \\
Age & 0.117 & 0.965 & 0.340 & -0.086 & 0.245 \\
\hline
\end{tabular}

Note: $\mathrm{a}<0.05$ is statistically significant.

Abbreviations: PASI, Psoriasis Area and Severity Index; BMI, body mass index; hs-CRP, high-sensitivity CRP.

significant difference in the ADA and duration between mild and moderate and mild and severe groups (Table 5).

\section{Discussion}

Though the etiology of psoriasis still remains unknown, the involvement of immunological disturbances cannot be denied. ADA is widely distributed with the highest activity in T-cells. ${ }^{12}$ Studies have shown increased serum ADA levels in diseases characterized by T-cell proliferation or activation., ${ }^{4}, 15$

Many contradictory results have been reported regarding ADA level in blood lymphocytes, with some studies showing normal and some reporting a higher value. Vlcek and Mikulíková reported higher ADA activity in peripheral blood lymphocytes. They also observed a significant decrease in ADA after treatment with methotrexate. ${ }^{13}$ Köse et al noticed decreased ADA activity in plasma and skin tissue from baseline value after treatment of psoriasis for 2 months. ${ }^{14}$ The elevated plasma ADA activity in psoriasis patients found in the present study seems to be in accordance with the previously mentioned two studies, whereas lizuka et $\mathrm{al}^{15}$ and Koizumi and Ohkawara ${ }^{4}$ observed a normal ADA level in peripheral blood lymphocytes and serum respectively $(P<0.001)$. Erbagci et al reported a drop in ADA after treatment of psoriasis $(P<0.001) .{ }^{16}$ Bukulmez et al found predominantly elevated ADA level in 25 psoriasis patients. ${ }^{5}$ The increase in ADA activity might be an indicator of activation of the immune system that might have originated from activation of T-lymphocytes in these patients. In addition, no previous reports concerning ADA activity in psoriasis patients have revealed a correlation between PASI scores and ADA activity. We observed a significant association of ADA with disease severity. Our results may provide insight into the usefulness of ADA as a potential marker of disease severity in psoriasis patients. 
Table 5 Comparison of variables with mild, moderate, and severe psoriasis

\begin{tabular}{|c|c|c|c|c|c|c|}
\hline Variables & $\begin{array}{l}\text { PASI <I0 (m) } \\
n=4 I\end{array}$ & $\begin{array}{l}\text { PASI I0-20(M) } \\
n=5\end{array}$ & $\begin{array}{l}\text { PASI >20 (S) } \\
n=4\end{array}$ & $\begin{array}{l}P \text {-value }{ }^{a} \\
\text { m vs } M\end{array}$ & $\begin{array}{l}P \text {-value }{ }^{a} \\
\text { m vs S }\end{array}$ & $\begin{array}{l}P \text {-value }{ }^{a} \\
M \text { vs S }\end{array}$ \\
\hline ADA & $28.16 \pm 10.11$ & $45.76 \pm 10.86$ & $53.8 \pm 11.28$ & 0.002 & 0.001 & 0.031 \\
\hline Uric acid & $6.7 \pm 1.38$ & $6.75 \pm 1.43$ & $6.88 \pm 1.08$ & 0.997 & 0.968 & 0.989 \\
\hline hs-CRP & $3.7 \pm 1.43$ & $3.84 \pm I .55$ & $3.97 \pm 1.38$ & 0.977 & 0.935 & 0.991 \\
\hline Duration & | $7.27 \pm 7.78$ & $30.0 \pm 12.73$ & $33.0 \pm 11.94$ & 0.009 & 0.003 & 0.863 \\
\hline
\end{tabular}

Notes: ${ }^{a}$ One-way post hoc ANOVA. $P<0.05$ considered statistically significant.

Abbreviations: PASI, Psoriasis Area and Severity Index; m, mild, M, moderate, S, severe; hs-CRP, high-sensitivity CRP.

The current study reported elevated serum uric acid level in psoriasis patients. However, a few studies have shown no significant increase in uric acid level, and no correlation was observed with the severity of the disease. ${ }^{17-19}$ In contrary to previous results, elevated uric acid levels are a frequent finding in psoriasis and an association does exist between them. This could be explained by the fact that psoriasis is a disorder of rapid epidermal turnover, which may lead to increased purine catabolism, thereby causing a rise in uric acid level. Proving this hypothesis, our result showed an increased serum uric acid level in psoriatic patients. However, previous reports have given conflicting results on the possible correlation between psoriasis extent and serum uric acid.

hs-CRP is an acute phase reactant which is raised in many inflammatory conditions. Its level can increase up to many folds within 24 hours and decrease to normal in a few days after treatment or spontaneously decrease after remission of disease. ${ }^{20,21}$ In this study we noticed an increase in hs-CRP level in patients and it was statistically significant when compared to healthy controls. Many previous studies have also reported the clinical utility of hs-CRP in psoriasis. ${ }^{8}$ Our findings are in accordance with the finding of Sergeant et al, who did not find any significant link between hs-CRP and PASI score in their study. ${ }^{22}$

Diverse findings regarding lipid profile have been reported in psoriasis. Studies done in recent years have shown a significant increase in TC, TAG, LDL, very low-density lipoprotein, and decrease in HDL in psoriasis patients as compared to non-psoriatic controls. ${ }^{23-26}$ The HDL-cholesterol was significantly decreased in our study, which is in agreement with previous studies, whereas Javidi et al, in his study, reported no difference in HDL level between psoriasis patients and controls. ${ }^{27}$ We did not find significant changes in the rest of the lipid profile like TC, TAG, and LDL, which is quite opposite to the findings of previous research. ${ }^{28,29}$ Considering the results of our study, the psoriasis patient could be at higher risk for cardiovascular events as justified by elevated inflammatory markers (hs-CRP) and decreased cardio-protective HDL level.

\section{Conclusion}

In conclusion, serum ADA activity is elevated in psoriasis patients and is associated with the severity of the psoriasis, therefore, it can be suggested as a serologic marker to assess disease severity. A decrease in ADA activity in psoriasis patients could play an important role in deciding whether to stop or lower treatment, when required. Our study also showed an increased level of uric acid and inflammatory marker hs-CRP in psoriatic patients, which can assist in management and follow-up treatment of patients. Psoriatic patients should also be evaluated and followed-up for the risk of dyslipidemia. Nevertheless, further prospective studies are required to support our suggestions.

\section{Acknowledgments}

We acknowledge the B.P. Koirala Institute of Health Sciences, Dharan, Nepal for providing the financial support for conducting the research under the institutional annual research grant scheme. We sincerely thank Mr Subodh Gupta, lab technologist, for helping us to perform the biochemical assays.

\section{Author contributions}

All the authors contributed to the conception of the study, its design, data collection, literature review, manuscript preparation, analysis and interpretation of data, editing, and proofreading the manuscript. All authors have final approval for publication and agree to be accountable for all aspects of the work.

\section{Disclosure}

The authors report no conflicts of interest in this work.

\section{References}

1. Adams A, Harkness RA. Adenosine deaminase activity in thymus and other human tissues. Clin Exp Immunol. 1976;26(3):647.

2. Zidek Z. Adenosine - cyclic AMP pathways and cytokine expression. Eur Cytokine Netw. 1999;10(3):319-328.

3. Baker BS, Fry L. The immunology of psoriasis. Br J Dermatol. 1992;126(1):1-9.

4. Koizumi H, Ohkawara A. Adenosine deaminase activity in sera of patients with psoriasis, mycosis fungoides and adult $\mathrm{T}$ cell leukemia. Acta Derm Venereol. 1992;72(6):410-412. 
5. Bukulmez G, Akan T, Ciliv G. Serum adenosine deaminase levels in patients with psoriasis: a prospective case-control study. Eur J Dermatol. 2000;10(4):274-276.

6. Isha, Jain VK, Lal H. C-reactive protein and uric Acid levels in patients with psoriasis. Indian J Clin Biochem. 2011;26(3):309-311.

7. Brenner W. \& Gschnait F. Serum uric acid levels in untreated and PUVA-treated patients with psoriasis. Dermatology. 1978;157(2): 91-95.

8. Strober B, Teller C, Yamauchi P, et al. Effects of etanercept on C-reactive protein levels in psoriasis and psoriatic arthritis. Br J Dermatol. 2008;159(2):322-330.

9. Kwon HH, Kwon IH, Choi JW, Youn JI. Cross-sectional study on the correlation of serum uric acid with disease severity in Korean patients with psoriasis. Clin Exp Dermatol. 2011;36(5):473-478.

10. das S, Biswas UK, Kumar A, Roy A. Study of serum carbonic anhydrase activity, uric acid, C-reactive protein levels and lipid parameters in patients with Psoriasis. Nepal Journal of Dermatology, Venereology \& Leprology. 2013;11(1):20-27.

11. Giusti G, Galanti B. Colorimetric method. Methods of enzymatic analysis. Weinheim: Verlag Chemie. 1984:315-323.

12. Woodley DT, Kim GH. Potential new insight into the pathogenesis of psoriasis. Arch Dermatol. 2009;145(6):713-714.

13. Vlcek F, Mikulíková D. [The effect of methotrexate on activity of T-lymphocyte marker enzymes in patients with psoriasis vulgaris]. Bratisl Lek Listy. 1995;96(3):137-140. Slovak.

14. Köse K, Utaş S, Yazici C, Akdaş A, Keleştimur F. Effect of propylthiouracil on adenosine deaminase activity and thyroid function in patients with psoriasis. Br J Dermatol. 2001;144(6):1121-1126.

15. Iizuka H, Koizumi H, Kimura T, Miura Y. Adenosine deaminase activity in peripheral lymphocytes of psoriasis and Sézary's syndrome. J Dermatol. 1980;7(3):165-169.

16. Erbagci Z, Erbagci AB, Köylüoglu O, Tuncel AA. Serum adenosine deaminase activity in monitoring disease activity and response to therapy in severe psoriasis. Acta Medica. 2006;49(2):101.
17. Chand R, Reddy BS, Sehgal VN, Datta P. Serum Uric Acid Calcium and Phosphorus in Psoriasis. Indian J Dermatol Venereol Leprol. 1983;49(4): 150 .

18. Lambert JR, Wright V. Serum uric acid levels in psoriatic arthritis. Ann Rheum Dis. 1977;36(3):264-267.

19. Scott JT, Stodell MA. Serum uric acid levels in psoriasis. In: Purine Metabolism in Man-I.V. US: Springer; 1984:283-285.

20. Steel DM, Whitehead AS. The major acute phase reactants: C-reactive protein, serum amyloid $\mathrm{P}$ component and serum amyloid A protein. Immunol Today. 1994;15(2):81-88.

21. Baumann H, Gauldie J. The acute phase response. Immunol Today. 1994;15(2):74-80.

22. Sergeant A, Makrygeorgou A, Chan WC, Thorrat A. Burden D. C-reactive protein in psoriasis. Br J Dermatol. 2008;158(2):417-419.

23. Taheri Sarvtin M, Hedayati MT, Shokohi T, Hajheydari Z. Serum lipids and lipoproteins in patients with psoriasis. Arch Iran Med. 2014;17(5):343.

24. Nemati H, Khodarahmi R, Rahmani A, Ebrahimi A, Amani M, Eftekhari K. Serum lipid profile in psoriatic patients: correlation between vascular adhesion protein 1 and lipoprotein (a). Cell Biochem Funct. 2013;31(1):36-40.

25. Asha K, Singal A, Sharma SB, Arora VK, Aggarwal A, Dyslipidaemia AA. Dyslipidaemia \& oxidative stress in patients of psoriasis: Emerging cardiovascular risk factors. Indian J Med Res. 2017;146(6):708.

26. Amer M, Galal A, Amer A. Psoriasis Severity is affected by T the Lipid Profile in Egyptian Patients. Gynecol Obstet. 2015;5(346):2161-2932.

27. Javidi Z, Meibodi NT, Nahidi Y. Serum lipids abnormalities and psoriasis. Indian J Dermatol. 2007;52(2):89.

28. Rocha-Pereira P, Santos-Silva A, Rebelo I, Figueiredo A, Quintanilha A, Teixeira F. Dislipidemia and oxidative stress in mild and in severe psoriasis as a risk for cardiovascular disease. Clin Chim Acta. 2001;303(1-2):33-39.

29. Uyanik BS, Ari Z, Onur E, Gündüz K, Tanülkü S, Durkan K. Serum lipids and apolipoproteins in patients with psoriasis. Clin Chem Lab Med. 2002;40(1):65-68
Psoriasis: Targets and Therapy

\section{Publish your work in this journal}

Psoriasis: Targets and Therapy is international, peer-reviewed, open access journal focusing on psoriasis, nail psoriasis, psoriatic arthritis and related conditions, identification of therapeutic targets and the optimal use of integrated treatment interventions to achieve improved outcomes

\section{Dovepress}

and quality of life. Visit http://www.dovepress.com/testimonials.php to read real quotes from published authors. 